\title{
Transformações econômicas e mudança linguística: a língua em Louveira/SP
}

DOI: http://dx.doi.org/10.21165/el.v48i2.2318

\section{Victor Carreão ${ }^{1}$}

\section{Resumo}

Partindo da hipótese de que variantes de prestígio de grandes cidades tendem a se espalhar para aglomerações urbanas menores, observamos, na cidade de Louveira/SP, diferentes traços linguísticos. Nos últimos anos, Louveira ganhou destaque na mídia ao ser classificada como um dos mais desenvolvidos municípios, em termos de PIB per capita e de qualidade de vida, no estado de São Paulo e no país. Essa rápida ascensão, fruto de diferentes incentivos fiscais por parte da prefeitura, levou-nos a observar como o comportamento linguístico dos louveirenses mudou com o tempo. Em especial, duas variáveis linguísticas serão abordadas aqui: (i) a realização das oclusivas dentais [t, d] diante da vogal [i]; e (ii) a realização de /r/ em posição de coda silábica. A proximidade com grandes centros urbanos e a passagem de uma economia agrícola para uma cultura de produção e serviços influenciaram o comportamento linguístico da geração que vivenciou essa mudança no estilo de vida louveirense.

Palavras-chave: variação linguística; mudanças econômicas; oclusivas dentais; retroflexão.

1 Universidade Estadual de Campinas (UNICAMP), Campinas, São Paulo, Brasil; vcarreao@yahoo.com.br; http://orcid.org/0000-0002-0866-1749 


\title{
Economic changes and linguistic changes: the speech in Louveira/SP
}

\begin{abstract}
Based on the hypothesis that variants of prestige of large cities tend to spread to smaller urban agglomerations, we observed, in the city of Louveira/SP, different linguistic traits. In recent years, Louveira has gained prominence in the media by being classified as one of the most developed municipalities, in terms of GDP per capita and quality of life, in the state of São Paulo and in the country. This rapid rise, as a result of different fiscal incentives on the part of the city hall, led us to observe how the language behavior in Louveira changed over time. In particular, two linguistic variables will be addressed here: (i) the realization of the dental occlusives [t, d] before the vowel [i]; and (ii) the realization of $/ r$ / in position of syllable coda. The proximity to large urban centers and the transition from an agricultural economy to a culture of production and services influenced the linguistic behavior of the generation that experienced this change in the Louveiran way of life.
\end{abstract}

Keywords: linguistic variation; economic changes; dental occlusives; retroflexion.

\section{Introdução}

Louveira é um pequeno município situado às margens da rodovia Anhanguera. Está a 71 quilômetros da capital do estado, São Paulo, e a 27 quilômetros de Campinas, uma das maiores cidades do interior paulista. Com pouco mais de 44.000 habitantes, a cidade é dividida, geograficamente, pela rodovia Anhanguera, em duas regiões conhecidas pelos louveirenses como: o Bairro Santo Antônio, região mais populosa e que é lar para muitos migrantes nordestinos; e a região do Centro, em que são encontrados muitos condomínios fechados. Há, também, uma área de proteção ambiental que totaliza pouco mais de $40 \%$ do território do município. Ao longo da rodovia Anhanguera, estão concentradas as principais empresas responsáveis pela ascensão na economia louveirense nos últimos 16 anos:

- Em 2012: a cidade de Louveira foi avaliada como a quarta melhor cidade para se morar no Brasil (G1, 2012);

- Em 2014: o município foi classificado como o mais desenvolvido do país - em uma análise que empregou como critério o PIB per capita² (AMARAL, 2014 e PRATES, 2014);

- Em 2015, de acordo com o índice Firjan de Desenvolvimento Municipal (IFDM), elaborado pela Federação das Indústrias do Rio de Janeiro, Louveira foi considerada a terceira cidade mais desenvolvida do Brasil e a primeira do estado de São Paulo

2 Produto Interno Bruto dividido pela quantidade de habitantes de uma região. 
(INFORMATIVO PTB, 2016, p. 08). Louveira também foi apontada como a melhor cidade com menos de 50 mil habitantes do País em sustentabilidade financeira (JORNAL DE JUNDIAÍ, 2015).

Conforme dados disponibilizados pelo IBGE (2016), no que diz respeito ao desenvolvimento de atividades dentro do próprio município, grande parte da população de Louveira desenvolve suas atividades profissionais e de estudos na própria cidade:

Quadro 1. Dados sobre deslocamento em Louveira

\begin{tabular}{|c|r|c|}
\hline \multirow{2}{*}{ Atividade dos habitantes } & \multicolumn{2}{|c|}{ Deslocamento } \\
\hline \multirow{3}{*}{ Escola } & $\mathbf{1 0 1 9 9}$ & \multicolumn{1}{c|}{ Detalhes } \\
\cline { 2 - 3 } & 8150 pessoas (80\%) & em Louveira \\
\cline { 2 - 3 } & 2049 pessoas (20\%) & em outro município \\
\cline { 2 - 3 } & $\mathbf{2 1 1 6 2}$ & \\
\hline \multirow{3}{*}{ Trabalho } & $16777(80 \%)$ & em Louveira \\
\cline { 2 - 3 } & $4065(19 \%)$ & em outro município \\
\cline { 2 - 3 } & $320(01 \%)$ & em dois ou mais municípios \\
\hline População total (2010) & 37125 & \\
\hline Pessoas não consultadas & 5764 & \\
\hline
\end{tabular}

Fonte: Adaptado de IBGE (2016).

Dos habitantes da cidade, $80 \%$ estudam ou trabalham em Louveira. Interessa-nos verificar como as mudanças no modo de vida louveirense, que, até antes da vinda das empresas para o município, era agrícola, pode ter influenciado o comportamento linguístico dos louveirenses. Para tanto, passemos à metodologia de pesquisa, que permitirá verificar quem são esses indivíduos e o que foi observado em suas produções de fala. 


\section{Metodologia}

Para este trabalho, foram realizadas 25 entrevistas sociolinguísticas ${ }^{3}$ (com cerca de 45 minutos cada e gravadas entre agosto de 2016 e agosto de 2017) com louveirenses que nasceram na cidade ou que se mudaram para ela até os 05 anos de idade. A ideia foi verificar, nestes indivíduos que cresceram em Louveira e puderam vivenciar a mudança na dinâmica social louveirense, como algumas variáveis linguísticas (detalhadas a seguir) se comportam. Os informantes que compõem a amostra foram selecionados de forma aleatória, seguindo três variáveis socioeconômicas: sexo/gênero (masculino ou feminino); região de residência na cidade (Centro ou Bairro); e faixa etária (de 18 a 29 anos, de 30 a 45 anos, e de 46 a 60 anos) - estas variáveis serão detalhadas mais adiante.

A plataforma R (R CORE TEAM, 2017) foi utilizada para rodar o teste de regressão logística, com a variável aleatória "informante" (visando evitar o enviesamento da amostra), mostrando quais variáveis sociais poderiam ter correlação com a realização de uma ou outra variante. Dessa maneira, é possível verificar como as variáveis socioeconômicas colocadas em foco podem influenciar, de forma conjunta ou não, a realização de determinadas variantes.

\subsection{As entrevistas sociolinguísticas}

Para o levantamento de dados referentes à fala louveirense, 25 indivíduos foram entrevistados conforme a metodologia de entrevista sociolinguística laboviana (LABOV, 2008 [1972]). A estratificação da amostra buscou contemplar a divisão dos falantes conforme:

- Sexo/gênero: masculino ou feminino;

- Região de residência em Louveira: Bairro ou Centro;

- Faixa etária: de 18 a 29 anos, de 30 a 45 anos e de 46 a 60 anos.

Outras variáveis sociais também foram controladas, mas não de forma ortogonal. Nos minutos finais da entrevista, os falantes foram questionados sobre a possível existência de um "sotaque" louveirense, ou de marcas linguísticas características dos louveirenses. Esse procedimento foi inspirado no trabalho de Kroch (1995). Os dados de fala levantados antes desse questionamento foram computados como "fala menos monitorada" e o levantamento após essa pergunta como "fala mais monitorada". Temos, assim, as seguintes variáveis não controladas:

3 A amostragem inicial previa 24 informantes. Uma entrevista adicional foi realizada, em que não há muita produção oral por parte do informante. Mesmo com pouca produção, alguns fatos interessantes sobre Louveira foram registrados e, por essa razão, essa entrevista foi mantida para a amostragem deste trabalho. 
- Ascendência: italiana ou não-italiana;

- Opinião sobre o sotaque louveirense: com sotaque ou sem sotaque;

- Momento de fala: mais controlado ou menos controlado.

As variáveis acima não apresentam ortogonalidade, uma vez que buscamos uma amostra aleatória - sem informação prévia sobre a ascendência dos informantes, ou de sua opinião sobre a fala louveirense. Em relação ao momento de fala, é interessante observar que, em alguns casos, os informantes tinham muito a dizer sobre o que pensavam da fala louveirense, chegando a citar sons que seriam "típicos de Louveira". Nestes casos, o tempo de fala "monitorada" (em que o falante sabia que estava sendo gravado e comentando sobre fenômenos linguísticos) foi maior do que em entrevistas em que os informantes não sabiam dizer se havia, ou não, sons particulares aos louveirenses. Neste trabalho, iremos nos ater às variáveis sociais controladas. Pensando em sexo/gênero, Louveira apresenta uma divisão balanceada com 51\% da sua população formada por homens e 49\% formada por mulheres (IBGE, 2016). Não há um registro oficial de quantos louveirenses moram na região do Bairro e do Centro, mas algumas reportagens apontam que, no Bairro, estaria concentrada a maior parte da população da cidade, com cerca de 25 mil pessoas (JORNAL DE JUNDIAÍ, 2015).

O quadro a seguir auxilia a verificar a distribuição da amostra, ressaltando o contexto social da cidade para cada faixa etária de entrevistados:

Quadro 2. Características dos informantes entrevistados

\begin{tabular}{|c|c|c|c|c|}
\hline & & ormant & & Contexto Social \\
\hline \multirow{8}{*}{ 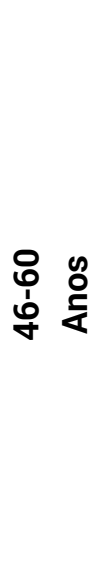 } & \multirow{4}{*}{ Centro } & Masc. & ie36 & \multirow{8}{*}{ Emancipação do município } \\
\hline & & Fem. & ie24 & \\
\hline & & Masc. & ie29 & \\
\hline & & Fem. & ie30 & \\
\hline & \multirow{4}{*}{ Bairro } & Masc. & ie22 & \\
\hline & & Fem. & ie41 & \\
\hline & & Masc. & ie39 & \\
\hline & & Fem. & ie42 & \\
\hline
\end{tabular}

(continua) 


\begin{tabular}{|c|c|c|c|c|}
\hline \multirow{8}{*}{ 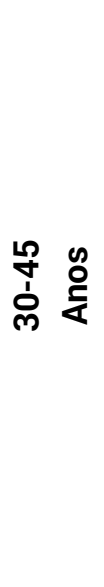 } & \multirow{4}{*}{ Centro } & Masc. & ie28 & \multirow{8}{*}{$\begin{array}{c}\text { Vinda de grandes empresas } \\
\text { para a cidade }\end{array}$} \\
\hline & & Fem. & ie31 & \\
\hline & & Masc. & ie44 & \\
\hline & & Fem. & ie35 & \\
\hline & \multirow{4}{*}{ Bairro } & Masc. & ie21 & \\
\hline & & Fem. & ie38 & \\
\hline & & Masc. & ie43 & \\
\hline & & Fem. & ie40 & \\
\hline \multirow{8}{*}{ 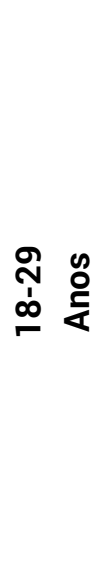 } & \multirow{4}{*}{ Centro } & Masc. & ie23 & \multirow{8}{*}{ Forte migração para a cidade } \\
\hline & & Fem. & ie18 & \\
\hline & & Masc. & ie17 & \\
\hline & & Fem. & ie19/ie25 & \\
\hline & \multirow{4}{*}{ Bairro } & Masc. & ie27 & \\
\hline & & Fem. & ie20 & \\
\hline & & Masc. & ie26 & \\
\hline & & Fem. & ie37 & \\
\hline
\end{tabular}

Fonte: Carreão (2018, p. 65).

Como dito anteriormente, as grandes empresas se instalaram em solo louveirense a partir do ano de 2002 - incentivadas pela Lei Complementar n 1.551/2002, Lei Complementar $n^{0} 1.602 / 2002$ e Lei Complementar $n^{\circ} 1.797 / 2006$. Esse período é o mesmo em que os falantes de nossa segunda faixa etária (de 30 a 45 anos) passaram por sua juventude. É interessante verificar que são estes falantes que apresentam o maior índice de variação para as duas variáveis linguísticas aqui observadas, como veremos mais adiante.

\section{As variáveis linguísticas}

Duas variáveis linguísticas serão abordadas a seguir: (i) a realização das oclusivas dentais [t, d] diante da vogal [i]; e (ii) a realização de /r/ em posição de coda silábica. 


\subsection{As oclusivas dentais [t, $d]$ diante de [i]}

A realização das oclusivas dentais [t, d] diante da vogal [i] é objeto de diferentes estudos no português brasileiro. A variação encontrada no Brasil, para esta variável, é a principal razão para a sua escolha como objeto de estudo. Em especial, observa-se o espalhamento da forma africada, [t]] e [dz], pelo país. Estas variantes, em termos de pontos de articulação, são realizadas de forma palatalizada:

[...] processo assimilatório no qual a parte frontal da língua se move em direção ao palato duro. Pode afetar tanto consoantes articuladas na região posterior da cavidade bucal, como $/ \mathrm{k} /, \mathrm{g} /$, quanto consoantes articuladas na região anterior da cavidade bucal, tais como /t/, /d/, /s/. (ABAURRE; PAGOTTO, 2013, p. 195).

Em diferentes comunidades de fala, são observados diferentes graus de palatalização. A forma palatalizada é, em muitos destes estudos, observada na fala de indivíduos mais jovens e que moram em regiões urbanas (como pode ser observado nos estudos de Pagotto, 2001; Matté, 2009; Mauri, 2008; Battisti et al., 2007). A escolha desta variável linguística é justificada não apenas pela observação de sua variação nos louveirenses, mas, também, pelo fato de Louveira possuir a divisão entre o urbano e o rural de uma maneira clara, estipulada em seu Plano Diretor.

Bortoni-Ricardo (2004) nos mostra que a conexão entre o urbano e o rural, em determinadas comunidades, existe em um continuum "rurbano" - ligado à teoria de Redes Sociais e à Acomodação Linguística. De forma resumida, esse continuum é observado em indivíduos que, estando entre o urbano e o rural, podem acomodar sua fala a seu dialeto de origem e, às vezes, ao dialeto novo trazido pela urbanização. Um exemplo desse continuum é observado em indivíduos que migram de uma cidade para outra, com sua fala pendendo para o dialeto de origem ou para o dialeto de chegada (da nova cidade em que estabeleceram residência).

A divisão trazida pela urbanização da cidade pode ser colocada no centro de nossa análise e, assim, é possível verificarmos como os falantes variam a realização das oclusivas dentais entre duas variantes: a forma dental [t, d] ou a forma africada [t $\left.\int, d_{3}\right]$.

\subsection{A realização de /r/ em posição de coda silábica}

A realização de /r/ em posição de coda silábica também é objeto de estudo de diferentes pesquisas no Brasil. A variedade de variantes que podem ser realizadas nessa posição silábica (em palavras como "porta" ou "mar") é extensa: são observadas "vibrantes apicais em Porto Alegre e São Paulo, fricativa velar em Rio de Janeiro e Salvador e aspirada em Recife" (CALLOU; MORAES; LEITE, 1996, p. 483). É comum associar cidades do interior 
paulista ao dialeto caipira (estudado por Amaral (1920) e Rodrigues (1974), entre outros pesquisadores), cuja variante para o /r/ em posição de coda silábica é a retroflexão: [I]. É interessante lembrar que esta variante não está restrita apenas ao estado de São Paulo, também sendo encontrada na região Sul, Sudeste e em outras localidades da região Centro-Oeste (NOLL, 2008).

Para os louveirenses, a realização desta variável é saliente. Muitos comentam que é uma marca que ajuda a identificar os migrantes nordestinos e que, naqueles que nasceram na cidade, é um "som" realizado de forma similar a outras cidades do interior. Mas também há aqueles que apontam que a realização de /r/ em coda silábica não é uma marca dialetal louveirense, pois não é tão diferente do que é produzido pelos paulistanos (que se assemelham aos comentários dos entrevistados de Leite (2011) em seu estudo sobre a realização de /r/ em coda silábica em Campinas). Nos comentários dos entrevistados, há um embate entre "capital" vs. "interior" que é reproduzido em duas variantes: o tepe [r] e a retroflexão [I].

A retroflexão não é, atualmente, associada apenas ao interior do estado de São Paulo. Na cidade de São Paulo, Oushiro (2015) registrou, em indivíduos da região periférica do município, alto índice da variante retroflexa, enquanto na região central houve alto índice da variante tepe. As duas variantes coexistem em um cenário urbano. Por vezes, a retroflexão carrega estigma (como, por exemplo, retrata Paes (2014), em seu trabalho em Lagoa Santa/MG) e é na possibilidade deste estigma - que, talvez, no imaginário popular remeta ao falar do "interior" - que esta variável foi observada nos falantes louveirenses.

\section{A variação na fala louveirense}

Como mencionado anteriormente, exploraremos o levantamento de dados das duas variáveis, observadas nas entrevistas sociolinguísticas, conforme as faixas etárias. Destarte, poderemos verificar como o contexto social por que passavam os louveirenses pode estar associado à variação/mudança linguística.

\subsection{A realização das oclusivas dentais $[t, d]$ antes de [i]}

A distribuição dos dados levantados para as oclusivas dentais [t, d] diante de [i], conforme as faixas etárias, é a seguinte: 
Tabela 1. Distribuição geral dos dados das oclusivas dentais

\begin{tabular}{c|c|c|c|c}
\hline Faixa etária & Africada & Dental & Total & Qui-quadrado \\
\hline 1a (18 a 29 anos) & $2413(99 \%)$ & $17(01 \%)$ & 2430 & \multirow{2}{*}{$\begin{array}{c}\mathbf{2}=\mathbf{1 8 1 7 , 4}(\mathbf{2}), \\
\boldsymbol{p}<\mathbf{0 , 0 0 1}\end{array}$} \\
\cline { 1 - 2 } $2 \mathrm{a}$ (30 a 45 anos) & $2186(90 \%)$ & $233(10 \%)$ & 2419 & \\
\hline 3a (46 a 60 anos) & $1324(54 \%)$ & $1115(46 \%)$ & 2439 & \\
\hline
\end{tabular}

Fonte: Adaptado de Carreão (2018, p. 96).

Como podemos observar nos dados acima, os falantes da terceira faixa etária (de 46 a 60 anos) são aqueles com a maior taxa de realizações da variante dental. A passagem da terceira faixa etária para a segunda registra uma queda expressiva nas ocorrências da variante dental. Dessa forma, a variante africada ganha espaço até predominar na fala dos indivíduos da primeira faixa etária (os louveirenses mais jovens). A queda no uso da variante dental pode ser observada no gráfico a seguir:

\section{Distribuição geral dos dados das Dentais}

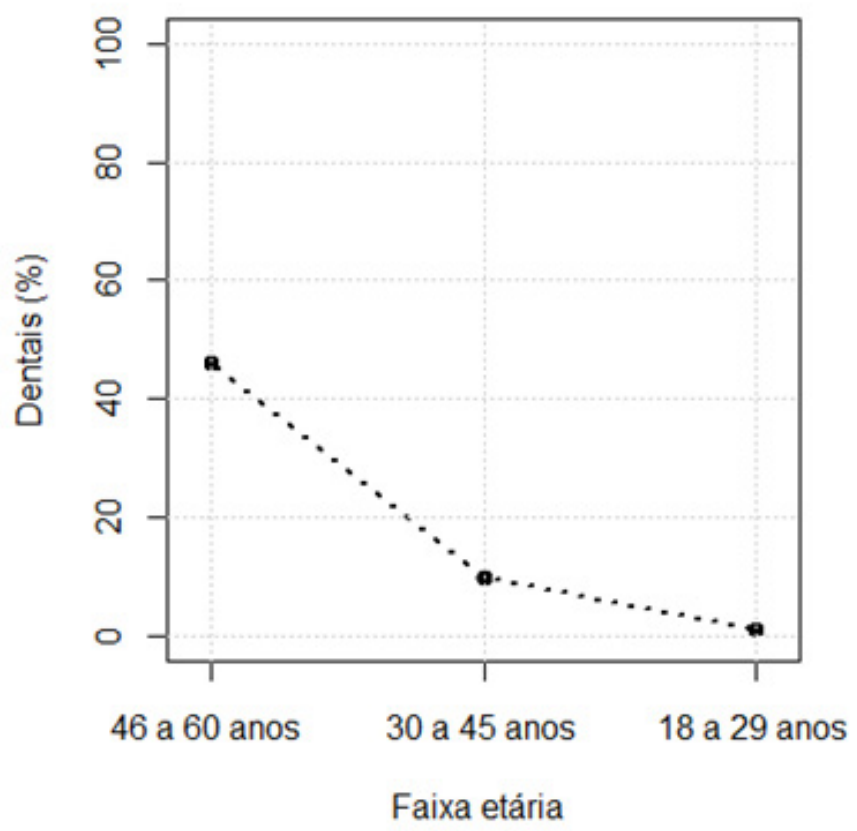

Gráfico 1. Realização das oclusivas /t/ e /d/ de forma dental, conforme a faixa etária

Fonte: Adaptado de Carreão (2018, p. 108). 
O gráfico acima ajuda a ilustrar os dados registrados na Tabela 1. Os falantes da segunda faixa etária são aqueles que iniciam o processo de mudança linguística, que, para os falantes mais jovens (da primeira faixa etária), já parece indicar um processo finalizado para a realização das oclusivas dentais [t, d] diante de [i]. Essa variável linguística é citada apenas em dois momentos - por duas entrevistadas diferentes - durante as entrevistas sociolinguísticas como uma marca de sotaque própria dos louveirenses. Os outros 23 louveirenses entrevistados não fazem menção a ela. A maior parte dos comentários sobre "marcas louveirenses na fala" aponta para a realização retroflexa do /r/ em coda silábica. Passemos à análise desta outra variável.

\subsection{A realização de /r/ em coda silábica}

A distribuição dos dados levantados para a realização de /r/ em posição de coda silábica, conforme as faixas etárias, é a seguinte:

Tabela 2. Distribuição geral dos dados de /r/ em coda

\begin{tabular}{|c|c|c|c|c|}
\hline Faixa etária & Retroflexo & Tepe & Total & Qui-quadrado \\
\hline 1a (18 a 29 anos) & 1209 (92\%) & $106(08 \%)$ & 1315 & \multirow{3}{*}{$\begin{array}{c}\chi^{2}=91,172(2), \\
p<0,001\end{array}$} \\
\hline 2a (30 a 45 anos) & $898(79 \%)$ & $232(21 \%)$ & 1130 & \\
\hline За (46 a 60 anos) & 1031 (89\%) & $124(11 \%)$ & 1155 & \\
\hline
\end{tabular}

Fonte: Adaptado de Carreão (2018, p. 114).

Os falantes da segunda faixa etária novamente se destacam. Desta vez, a realização da variante tepe é observada com maior frequência em suas falas. Não há muitas diferenças entre a terceira e a primeira faixa etária, mas o destaque dos falantes de 30 a 45 anos nos chama a atenção aqui. O gráfico abaixo ilustra os valores da tabela acima: 


\section{Distribuição geral dos dados dos Tepes}

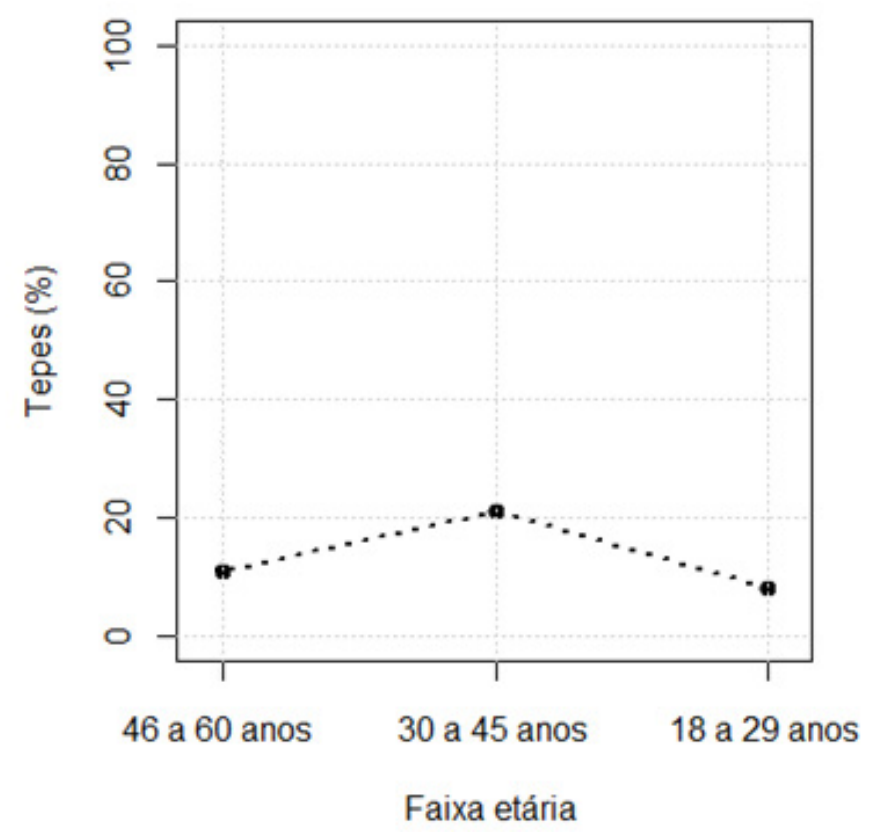

Gráfico 2. Realização de /r/ em coda silábica como tepe para todas as faixas etárias

Fonte: Adaptado de Carreão (2018, p. 128).

Há quase o dobro de ocorrências da variante tepe, quando comparamos a taxa de realização da terceira faixa etária com a segunda. Esse destaque remete ao que Labov (2008 [1972]) classifica como "hipercorreção": o uso exagerado de determinado traço linguístico que possa carregar prestígio. Pensando no uso de formas linguísticas consideradas prestigiosas, é possível entender a variação acima nos mesmos moldes da pesquisa de Labov (2008 [1972]) sobre o apagamento do rótico em posição medial ou final de palavra, nas lojas de departamento de Nova York: os valores linguísticos são ditados pelos mais jovens, com mais possibilidades de empregabilidade - mostrando que a idade não é uma variável que poderia ser considerada de forma isolada para a análise. Ainda no estudo de Labov (2008 [1972]), em uma análise da fala monitorada de informantes mais velhos, a variação linguística se mostra como uma reafirmação destes informantes frente à instabilidade profissional, devido à idade mais avançada.

A valoração da variante tepe é encontrada em comentários feitos pelos entrevistados durante as entrevistas sociolinguísticas, como visto em uma das informantes:

IE38: eu acho que eu falo bem puxado. Assim, o "erre"... eu percebo muito, assim, que agora eu trabalho em São Paulo, né, e aí eu vou pra lá conversar com um pessoal e eu percebo que é totalmente 
diferente a forma de puxar, o interior. É o interior [com [.I]], a carne [com [r]], sai esse puxado, né?! Eu falo "ah, meu Deus, queria puxar menos esse 'erre' pra não ficar tão característico" (risos)

Perceber as diferenças nas formas variantes de / $\mathrm{r} /$ em coda silábica e atribuir diferentes valores a elas - associados à mobilidade social - é um ponto de partida para entender a taxa de realização da variante tepe para os falantes da segunda faixa etária. É interessante, também, perceber a menção ao "trabalho", pois é neste ambiente que a diferenciação entre as duas formas variantes é feita. E é nesse eixo entre "trabalhar em Louveira" ou "trabalhar fora de Louveira" que podemos entender o caminho que a variação linguística toma: os falantes da segunda faixa etária crescem em uma Louveira em que trabalhar na dinâmica agrícola da cidade está se tornando passado, ao passo que trabalhar em empresas seria fazer parte do novo, do desenvolvimento vindo de grandes cidades. A mudança na dinâmica econômica da cidade, que alterou o estilo de vida louveirense, ajuda a explicar as ideias que repousam no imaginário louveirense.

\subsection{A atividade profissional e a variação}

Antes de passarmos às reflexões finais deste trabalho, é interessante observar como a atividade profissional dos louveirenses pode estar correlacionada à variação. Como observado anteriormente, a segunda faixa etária foi aquela que viveu a transição socioeconômica em Louveira - de uma cidade de características rurais para um grande polo logístico. Dos informantes da segunda faixa etária (de 30 a 45 anos), destacamos, abaixo, as mulheres (aquelas em que houve maior número de ocorrências para a variante dental $[t, d]$ ):

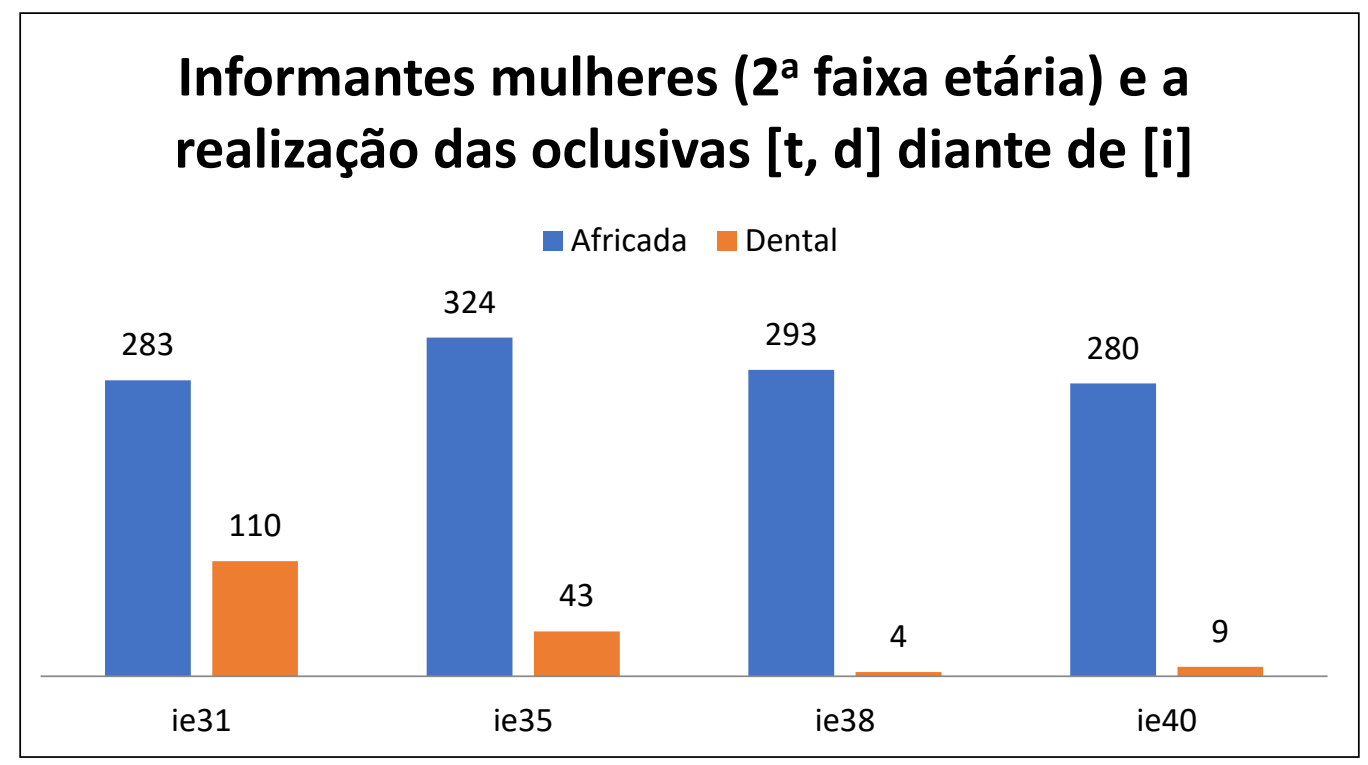

Gráfico 3. Informantes mulheres e a realização das oclusivas [t, d] diante de [i]

Fonte: Elaboração própria. 
A informante IE31 trabalhou por um curto período em uma cidade da região e, no momento da entrevista sociolinguística, trabalhava na cidade, enquanto IE35 sempre trabalhou em pequenos comércios de Louveira. Embora a atividade profissional não seja no mesmo tipo de serviço, as duas informantes trabalham com serviço social - diretamente com a comunidade, atendendo moradores de todas as classes sociais da cidade e aqueles que ali sempre viveram. Da segunda faixa etária, essas são as duas informantes que têm maior contato com a população louveirense no geral. Essas mesmas informantes são aquelas que apresentam o maior número de tepes para a variável de /r/ em posição de coda silábica também.

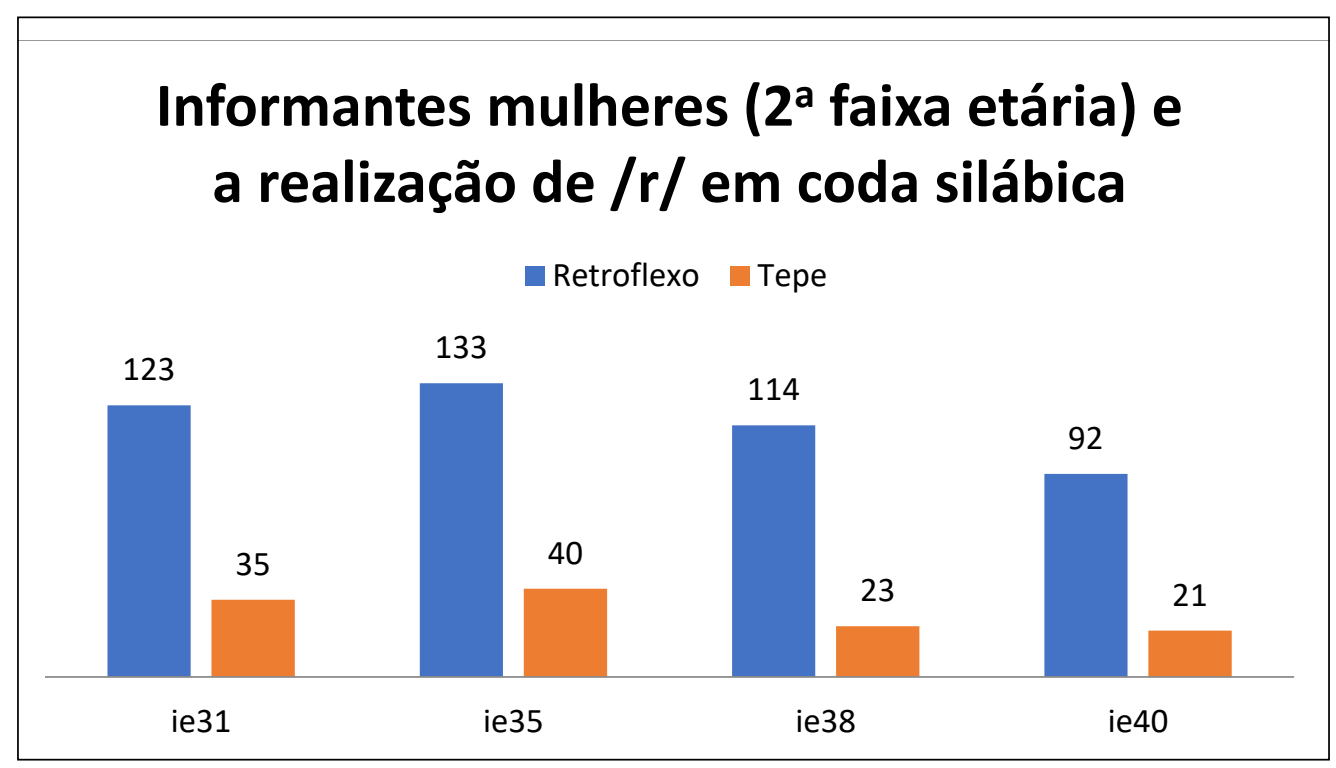

Gráfico 4. Informantes mulheres ( $2^{a}$ faixa etária) e a realização de /r/ em coda silábica

Fonte: Elaboração própria.

É interessante verificar como essas duas informantes variam no que poderia ser chamado de formas mais tradicionais louveirenses (a realização e $[t, d]$ ) e formas mais inovadoras (a realização de tepe, para /r/ em coda silábica). A variação nesse continuum nos permite traçar algumas considerações.

\section{Mudanças econômicas, reflexos linguísticos}

A saliência da variável /r/ em coda silábica é maior do que a realização das oclusivas dentais [t, d] diante da vogal [i]. Como prováveis causas para a saliência fonética, Trudgill (1986) aponta três: a distância fonética entre as variantes de duas variedades de fala; o estigma que uma ou outra forma linguística pode carregar e a presença ou ausência de uma unidade fonológica em comum para as duas variedades de fala que estão em contato. Parece-nos que a valoração das formas, o prestígio atribuído a cada variante, está em jogo aqui. 
A economia de tempos passados se modifica e deixa de ser centrada na agropecuária. As grandes empresas ganham terreno no município e os louveirenses são a mão de obra para essa nova fase da cidade. Como é, então, o comportamento linguístico dos louveirenses da segunda faixa etária que se mantiveram em atividades profissionais em pequenos comércios da cidade e daqueles que trabalham em empresas (dentro ou fora de Louveira)? As ocorrências das oclusivas dentais [t, d] diante de [i] apresentaram grande variação para duas informantes (como visto anteriormente). Pensando em como os informantes da segunda faixa etária vivenciaram a mudança na dinâmica socioeconômica de Louveira, é interessante olhar as ocorrências individuais dos informantes para as duas variáveis estudadas em nosso trabalho. A tabela abaixo mostra as ocorrências das oclusivas dentais [t, d] diante de [i] para cada um dos entrevistados da segunda faixa etária:

Tabela 3. Distribuição geral dos dados das oclusivas dentais [t, $d]$ para os falantes da segunda faixa etária

\begin{tabular}{|c|c|c|c|c|c|}
\hline Informante & Africada & Dental & TOTAL & Curso & $\begin{array}{c}\text { Experiência profissional } \\
\text { (fora de Louveira) }\end{array}$ \\
\hline \multicolumn{6}{|c|}{$2^{\text {a }}$ Faixa etária } \\
\hline IE21 & 178 (99\%) & $01(01 \%)$ & 179 & S & $S$ \\
\hline IE28 & 391 (100\%) & $00(0 \%)$ & 391 & S & $S$ \\
\hline IE31 & $283(72 \%)$ & $110(28 \%)$ & 393 & $\mathbf{N}$ & $S$ \\
\hline IE35 & 324 (88\%) & $43(12 \%)$ & 367 & $\mathbf{N}$ & $\mathbf{N}$ \\
\hline IE38 & 293 (97\%) & 04 (03\%) & 297 & S & S \\
\hline IE40 & $279(97 \%)$ & $09(03 \%)$ & 288 & N & $N$ \\
\hline IE43 & $153(72 \%)$ & $60(28 \%)$ & 213 & $\mathbf{N}$ & $\mathbf{N}$ \\
\hline IE44 & 285 (98\%) & 06 (02\%) & 291 & $N$ & $S$ \\
\hline TOTAL & 2186 (90\%) & $233(10 \%)$ & 2419 & - & - \\
\hline
\end{tabular}

Fonte: Elaboração própria.

Já para a realização de /r/ em posição de coda silábica, os falantes da segunda faixa etária apresentam a seguinte distribuição de dados: 
Tabela 4. Distribuição geral dos dados de /r/ em coda silábica para os falantes da segunda faixa etária

\begin{tabular}{c|c|c|c|c|c}
\hline \multirow{2}{*}{ Informante } & Retroflexo & Tepe & TOTAL & Curso & $\begin{array}{r}\text { Experiência } \\
\text { profissional }\end{array}$ \\
\hline \multicolumn{5}{c}{$\mathbf{2}^{\text {a }}$ Faixa Etária } \\
\hline IE21 & $65(71 \%)$ & $\mathbf{2 7}(\mathbf{2 9} \%)$ & 92 & $\mathbf{S}$ & $\mathbf{S}$ \\
\hline IE28 & $147(67 \%)$ & $\mathbf{7 3}(\mathbf{3 3} \%)$ & 220 & $\mathbf{S}$ & $\mathbf{S}$ \\
\hline IE31 & $123(78 \%)$ & $\mathbf{3 5}(\mathbf{2 2} \%)$ & 158 & $\mathbf{N}$ & $\mathbf{S}$ \\
\hline IE35 & $133(77 \%)$ & $\mathbf{4 0}(\mathbf{2 3} \%)$ & 173 & $\mathbf{N}$ & $\mathbf{N}$ \\
\hline IE38 & $114(83 \%)$ & $23(17 \%)$ & 137 & $\mathrm{~S}$ & $\mathrm{~S}$ \\
\hline IE43 & $92(81 \%)$ & $21(19 \%)$ & 113 & $\mathrm{~N}$ & $\mathrm{~N}$ \\
\hline IE44 & $98(93 \%)$ & $7(07 \%)$ & 105 & $\mathrm{~N}$ & $\mathrm{~N}$ \\
\hline TOTAL & $\mathbf{8 9 8}(\mathbf{7 9} \%)$ & $\mathbf{2 3 2}(\mathbf{2 1} \%)$ & 1130 & - & $\mathrm{S}$ \\
\hline
\end{tabular}

Fonte: Elaboração própria.

Em destaque, nas tabelas acima, estão as maiores porcentagens de ocorrências para as duas variáveis linguísticas: acima de 10\% de realizações da variante dental (que é a taxa média de ocorrências desta variante para esta faixa etária); e acima de $21 \%$ de realizações da variante tepe (que é a taxa média de ocorrências desta variante para esta faixa etária). Também constam, nas últimas duas colunas da tabela, se os informantes possuem formação educacional (de nível técnico ou superior) voltada a atividades do mundo corporativo (administração, contabilidade, logística, recursos humanos, etc.) e se já trabalharam em empresas de médio ou grande porte ("S" para "sim" e "N" para "não"). Não ter feito curso para atuar no mundo corporativo não implica em não ter feito nenhum tipo de curso como educação técnica ou superior. Empresas de médio/grande porte são aquelas com 50 colaboradores ou mais.

Não há um padrão nas tabelas acima, mas é possível observar que, para a realização das oclusivas dentais [t, d] diante da vogal [i], os entrevistados sem experiências relacionadas ao mundo corporativo (seja em termos de estudos ou de experiência de trabalho) apresentam maiores taxas de realização para a variante dental. A única exceção é a entrevistada IE40, que viveu por alguns anos fora de Louveira e que para lá se mudou ainda na infância. Não ter algum tipo de contato com a nova dinâmica econômica parece ser um indicador de que a variante dental pode estar presente na fala. 
Pagotto (2001, p. 293) aponta que a "variação é discurso e as formas variantes são disputadas pelas formações discursivas para significar nelas". Em sua tese, Pagotto (2001, p. 294) traça uma interessante hipótese em relação à variação observada para as oclusivas dentais [t, d] diante de [i] em informantes de Florianópolis/SC: ao registrar o uso da variante africada alveolar [ts, dz] - fugindo dos extremos da palatalização como $\left[\mathrm{t} \int, d_{3}\right]$ e da forma dental [t, d] - questiona se esta variante não seria "uma espécie de 'terceira via', a possibilidade de ser moderno, distanciando-se do atraso que a variante não africada representaria, sem, no entanto, abrir mão da natividade". É possível dizer que este mesmo "jogo" entre o moderno e o tradicional é visível na variação louveirense de que tratamos aqui.

Em relação à realização de /r/ em coda silábica, a variante tepe aparece com mais frequência na fala daqueles que frequentaram algum tipo de curso voltado à gestão ou que tiveram experiência de trabalho em médias e grandes empresas. A exceção é a falante IE35, que, mesmo sem esses dois tipos de experiência, realiza a variante tepe acima da média para a segunda faixa etária. As tabelas nos ajudam a verificar como tal ligação entre a mudança na dinâmica de vida de uma comunidade e a variação linguística podem estar relacionadas. No caso das oclusivas dentais, a frequência do contato com indivíduos que realizem outras formas variantes pode estar relacionada à implementação da variante africada. Para o /r/ em coda silábica, variável mais saliente para os louveirenses, a atividade profissional parece ser um dos fatores que merece maior detalhamento.

\section{Considerações finais}

Fechamos este artigo com sugestões de pesquisa. Ao que tudo indica, há uma relação entre a dinâmica profissional de uma comunidade com a variação linguística. Esse eixo deve ser explorado mais detalhadamente em pesquisas futuras, uma vez que os resultados apontam para uma relação interessante entre economia e variação linguística.

Mudanças econômicas transformam as comunidades. Em cidades pequenas, este fenômeno é mais facilmente observado e a nova dinâmica de vida - junto às modificações no espaço físico - é perceptível a todos que ali vivem. Louveira é um exemplo de comunidade pequena, criada há pouco mais de 50 anos em um processo de emancipação do município, em que as mudanças urbanas foram facilmente visualizadas por seus moradores. É interessante verificar que as mudanças linguísticas caminham lado a lado com a dinâmica de vida de uma comunidade.

A segunda faixa etária (de 30 a 45 anos) se encontra entre uma Louveira antiga/tradicional e uma Louveira urbana/moderna. É nesse eixo que o continuum é estabelecido para as variáveis aqui observadas: as oclusivas dentais [t, d] diante de [i] com algum resquício de realização nos informantes imersos na vida da comunidade louveirense - desaparecendo 
na fala dos mais jovens (da primeira faixa etária); e a realização de /r/ em posição de coda silábica com o registro de tepes para os informantes presentes na modernidade/ urbanidade (louveirense ou não). É a coexistência dessas diferentes variantes que capta o ouvido dos sociolinguistas que, na dinâmica socioeconômica da cidade, pode verificar como operam os eixos da variação.

Pesquisar esse fenômeno em cidades pequenas que passam por processos econômicos similares é intrigante a fim de se verificar os caminhos pelos quais a variação linguística - para determinadas variáveis - se espalha.

\section{REFERÊNCIAS}

ABAURRE, M. B. M.; PAGOTTO, E. G. Consoantes em ataque silábico: palatalização de /t, d/. In: ABAURRE, M. B. (org.). Gramática do Português Culto Falado no Brasil. v. VII. A Construção Fonológica da Palavra. São Paulo: Contexto, 2013.

AMARAL, A. O Dialecto Caipira. São Paulo: Editora O Livro, 1920.

AMARAL, R. Segundo estudo, Louveira é a cidade mais desenvolvida do país. Jornal de Jundiaí, Jundiaí, 03 jun. 2014. Região. Disponível em: http://www.jj.com.br/noticias-1144segundo-estudo-louveira-e-a-cidade-mais-desenvolvida-do-pais. Acesso em: 03 maio 2015.

BATTISTI, E.; DORNELLES FILHO, A. A.; LUCAS, J. I. P.; BOVO, N. M. P. Palatalização das oclusivas alveolares e a rede social dos informantes. Revista Digital de estudos da linguagem - REVEL, v. 5, n. 9, p. 1-29, ago. 2007.

BORTONI-RICARDO, S. M. Educação em língua materna: a sociolingüística na sala de aula. São Paulo: Parábola Editorial, 2004.

CALLOU, D.; MORAES, J. A.; LEITE, Y. Variação e diferenciação dialetal: a pronúncia do /r/ no português do Brasil. In: KOCH, I. G. V. (org.). Gramática do português falado. v. VI: desenvolvimentos. Campinas: Editora da UNICAMP, 1996. p. 465-493.

CARREÃO, V. Transformações econômicas e mudança linguística: a língua em Louveira/ SP. 2018. Dissertação (Mestrado em Linguística) - Instituto de Estudos da Linguagem, Universidade Estadual de Campinas, Campinas, 2018.

G1. Indaiatuba é a ${ }^{\text {a }}$ do país em ranking das melhores cidades para se viver. G1, Campinas, 02 dez. 2012. Campinas e Região. Disponível em: https://glo.bo/2JfMyWE. Acesso em: 03 maio 2015. 
IBGE (Instituto Brasileiro de Geografia e Estatística). Louveira. 2014. Disponível em: http:// bit.ly/2XtF774. Acesso em: 03 maio 2015.

IBGE (Instituto Brasileiro de Geografia e Estatística). Louveira: Panorama. 2016. Disponível em: https://cidades.ibge.gov.br/v4/brasil/sp/louveira/panorama. Acesso em: 28 jun. 2017.

INFORMATIVO PTB. Nossa Cidade Louveira. Informativo - Jan. 2013 a Jun. 2016. Revista informativa do Diretório Municipal do Partido Trabalhista Brasileiro - Louveira, 2016.

JORNAL DE JUNDIAÍ (JJ). Louveira recebe prêmio nacional. JJ Região, 22 set. 2015. Disponível em: http://www.jj.com.br/noticias-20841-louveira-recebe-premio-nacional-. Acesso em: 04 mar. 2017.

$\mathrm{KROCH}, \mathrm{A}$. Dialect and Style in the Speech of Upper Class Philadelphia. In: GUY, G.; BAUGH, J.; SCHIFFRIN, D.; FEAGIN, C. (org.). Towards a Social Science of Language: Papers in Honor of William Labov. Philadelphia: John Benjamins, 1995.

LABOV, W. Sociolinguistic Patterns. Philadelphia: University of Pennsylvania Press. Padrões Sociolinguísticos. Tradução Marcos Bagno, Marta Scherre e Caroline Cardoso. São Paulo: Parábola, 2008 [1972].

LEITE, C. M. B. Atitudes linguísticas e teoria da acomodação: inter-relação entre Sociolinguística e Psicologia Social. Estudos Linguísticos, v. 40, n. 2, p. 1017-1028, 2011.

MATTÉ, G. D. A palatalização variável de /t d/ em Caxias do Sul. Cadernos do IL, n. 38, p. 43-55, 2009.

MAURI, C. Palatalização das oclusivas alveolares e práticas sociais em capelas de forqueta, Caxias do Sul (RS). 2008. Dissertação (Mestrado em Letras e Cultura Regional) Universidade de Caxias do Sul, Caxias do Sul, 2008.

NOLL, V. O português brasileiro: formação e contrastes. São Paulo: Globo, 2008.

OUSHIRO, L. Identidade na pluralidade: avaliação, produção e percepção linguística na cidade de São Paulo. 2015. Tese (Doutorado em Semiótica e Linguística geral) - Faculdade de Filosofia, Letras e Ciências Humanas, Universidade de São Paulo, São Paulo, 2015.

PAES, M. H. S. A variável (R) em coda silábica medial no bairro várzea, em Lagoa Santa-MG. 2014. Dissertação (Mestrado em Letras) - Faculdade de Letras, Universidade Federal de Minas Gerais, Belo Horizonte, 2014. 
PAGOTTO, E. G. Variação é identidade. 2001. Tese (Doutorado em Linguística) - Instituto de Estudos da Linguagem, Universidade Estadual de Campinas, Campinas, 2001.

PRATES, M. O ranking definitivo das cidades mais desenvolvidas do país. Revista Exame online, São Paulo, 08 jun. 2014. Campinas e Região. Disponível em: http://bit.ly/2RTUqzG. Acesso em: 03 maio 2015.

R CORE TEAM. R: A language and environment for statistical computing. R Foundation for Statistical Computing, Vienna, Austria, 2017. Disponível em: http://www.R-project.org. Acesso em: 25 mar. 2017.

RODRIGUES, A. N. O dialeto caipira na região de Piracicaba. São Paulo: Ática, 1974.

TRUDGILL, P. Dialects in Contact. Oxford: Basil Blackwell, 1986. 